\title{
O escritor migrante e a ficção diaspórica
}

\section{The migrant writer and the diasporic fiction}

Shirley de Souza Gomes Carreira ${ }^{1}$

\section{RESUMO}

Em Imaginary Homelands, Salman Rushdie afirma que escritores migrantes, como ele, que pertencem a dois mundos ao mesmo tempo, posto que têm sido transportados através do mundo, são homens traduzidos. O homem híbrido está na confluência das misturas, das transformações, nas combinações de novas culturas, idéias e políticas. É, portanto, um homem que não pode pensar em si mesmo como o fruto de uma identidade condicionada ao que Marc Augé denomina "lugar antropológico". Este artigo analisa o romance Fúria, de Salman Rushdie, a fim de demonstrar como a obra retrata a questão da identidade do ponto de vista de um escritor migrante.

Palavras-chave: Identidade. Migração. Representação.

\section{ABSTRACT}

In Imaginary Homelands, Salman Rushdie says that migrant writers, who belong to different worlds and have been transported through the world, are translated men. A hybrid man is in the confluence of blending, changes and in the combination of new cultures, ideas and policies. Thus, he is a man that cannot think of himself as being the product of an identity that is conditioned to what Marc Augé defined as "anthropological place". This article focuses on the novel Fury, by Salman Rushdie, in order to show how it portrays the issue of identity from the migrant writer's viewpoint.

Key Words: Identity. Migration. Representation.

\footnotetext{
${ }^{1}$ Doutora em Literatura Comparada, pela UFRJ. Pós-doutora em Literaturas de Língua Inglesa, UERJ, Coordenadora do Curso de Letras da UNIGRANRIO.
} 


\section{INTRODUÇÃO}

Ao longo dos séculos, a migração tem sido interpretada como uma condição natural da experiência humana e os múltiplos processos de aculturação dos indivíduos migrantes têm sido alvo de inúmeras pesquisas científicas de áreas tais como a Sociologia, a Antropologia e, mais recentemente, a Literatura.

No contexto da globalização, a migração assume o caráter de fenômeno sociocultural contemporâneo, muito embora não se possa ignorar seu papel preponderante em períodos críticos da história humana, como, por exemplo, na segunda metade do século XX, quando a Europa, devastada pela Segunda Guerra Mundial, necessitou de mão-de-obra estrangeira para tornar possível a reconstrução dos países envolvidos no conflito bélico. Esse, dentre outros fatores, concorreu para recompor as relações entre os chamados países "centrais" e os "periféricos".

Esse processo migratório propiciou a formação de "enclaves" étnicos minoritários no interior dos estados-nação do Ocidente, levando a uma "pluralização" de culturas e identidades nacionais.

O antigo quadro de homogeneidade e de proximidade com a cultura ocidental, observado antes do início dos grandes fluxos migratórios, se reverteu, dando lugar à heterogeneidade que, à medida que os imigrantes temporários tornaram-se residentes estáveis, veio a gerar um comportamento xenofóbico em alguns países.

A diversidade cultural não se manifestou apenas nas práticas sociais, mas também em uma forma específica de escrita que, mais tarde, veio a ser reconhecida como "literatura de migração". Essa literatura expressava os estágios de aculturação pelos quais passavam os migrantes. Se, por um lado, uma boa parte das obras assim rotuladas refletia a assimilação da cultura dos países de adoção, por outro lado, havia, igualmente, uma literatura de migração que a ela resistia, primando por uma característica saudosista e pelo culto às raízes. Mais recentemente, observouse o fenômeno da transculturação ${ }^{2}$, termo criado pelo antropólogo Fernando Ortiz (1940) e retomado nos estudos literários por Angel Rama. Esse fenômeno deu

\footnotetext{
2 O antropólogo cubano Fernando Ortiz criou o termo "transculturação" para definir um modo
} de aculturação em que ambos os segmentos se modificam, gerando novas configurações identitárias. 
origem a indivíduos com identidades híbridas e a literatura de migração por eles produzida apresenta características transculturais.

O fim do imperialismo e a focalização no pós-colonialismo contribuíram para uma redescoberta literária do Oriente e não há dúvida quanto ao fato de que o caminho para a visibilidade da literatura indiana contemporânea de expressão inglesa foi aberto por Salman Rushdie, escritor indo-britânico, que, na experiência do exílio, trouxe a Índia para o centro das atenções ao ser condenado à morte pelo Aiatolá Khomeini.

Um exame detalhado da obra de Rushdie revela a tensão gerada por uma identidade que está fundamentada em duas culturas diferentes, e que se manifesta sob uma forma de negociação com a nova cultura, ao mesmo tempo em que se dá um desenraizamento parcial em relação à cultura de origem. Esse novo olhar sobre a diversidade corresponde ao conceito derridiano de différance, ou seja, à substituição de binarismos por localizações posicionais e relacionais, que subvertem os modelos culturais tradicionais orientados para a nação.

Rushdie opta por escrever na língua do ex-colonizador: o inglês. Essa opção tem dois objetivos claros, segundo o próprio autor: relatar a sua experiência de "homem traduzido" (RUSHDIE, 1991, p.16), exposto à cultura de três países distintos (Índia, Paquistão e Inglaterra), e denunciar o efeito pernicioso da tradição sobre os indivíduos, ao perpetuar uma "mentalidade de gueto". Essa recriação é fruto da ótica do escritor migrante, um indivíduo que, segundo o autor, tem de enfrentar cotidianamente os problemas de definição, a dupla perspectiva de quem se vê, a um só tempo, dentro e fora da sociedade em que vive.

Viver essa experiência significa ver-se obrigado a negociar com as novas culturas, sem ser totalmente assimilado por elas e sem perder completamente a própria identidade. A idéia de pureza cultural, ou de absolutismo étnico, jamais poderá ser associada à sua história.

O homem híbrido está na confluência das misturas, das transformações, nas combinações de novas culturas, idéias e políticas (RUSHDIE, 1991, p.394). É, portanto, um homem que já não pode pensar em si mesmo como o fruto de uma identidade condicionada ao que Marc Augé denomina "lugar antropológico" (AUGÉ, 1994, p.42). 
Se outrora a identidade era definida por um sentimento de pertencimento a uma comunidade, ao compartilhamento de elementos tais como o idioma e a cultura, a pós-modernidade reconhece que todos os fatores identitários são, na realidade, entidades produzidas dentro de um sistema de representação cultural, configurando o que Edward Said chama de "geografia imaginária" (SAID, 1990).

Ao descobrir que, para preservar a sua estabilidade e perpetuar a sua expansão, o ocidente inventou representações de si e do outro, a fim de exercer a sua capacidade e vontade de domínio, os indivíduos oriundos de culturas "colonizadas" buscaram a única saída que julgavam plausível para tornar audível a própria voz: migrar, adquirir a cultura do colonizador para, então, enunciar, a partir de um novo locus, o seu discurso.

Em Fúria ${ }^{3}$, Rushdie narra a saga de um ex-professor de História das Idéias que exemplifica bem o homem que é o produto das novas diásporas criadas pelas migrações pós-coloniais.

Após encerrar a sua carreira acadêmica em Cambridge, Malik Solanka volta a se dedicar a um antigo hobby: a confecção de bonecos de madeira. Uma de suas criações, a boneca Little Brain, acaba por virar celebridade televisiva, em um programa em que viaja no tempo e entrevista os grandes filósofos da história.

Ao ver que o poder da mídia suplantara as suas convicções intelectuais e éticas, Solanka abandona a família e foge para Nova York, tentando dominar em si aquilo que considera o mal do mundo contemporâneo: a fúria.

Essa tentativa, no entanto, dá início a um doloroso mergulho no passado que ele tenta, inutilmente, apagar. Em seu ritual de passagem, defronta-se com três mulheres que exercem papel preponderante nesse processo de confronto da personagem consigo mesma: Eleanor, a esposa que abandonara sem nenhuma explicação, Mila, que representa o mergulho no espaço dos interditos sociais e morais, e Neela, o amor total e libertador.

Este ensaio propõe analisar a trajetória do migrante, que em busca de uma razão para a própria vida, segue um caminho inverso, desfragmentando a sua atual

3 Todas as citações do romance são de Rushdie: 2003; doravante serão apenas citados os números das páginas da obra. 
identidade, pela via da memória, tentando encontrar, em algum lugar do passado, a origem da fúria.

Solanka, o protagonista, assim como o próprio Rushdie, é um indivíduo migrante, um homem traduzido. $E$, como tal, está sujeito à dupla conseqüência de conviver com o poder hegemônico, combater e/ou estar irremediavelmente atraído por ele, e o romance nos revela esse dado já no primeiro capítulo:

\begin{abstract}
A América insultava o resto do planeta, pensou o antiquado Malik Solanka, tratando aquela opulência com o descaso do encolher de ombros da riqueza nada igualitária. Mas Nova York nessa época de plenitude tornarase objetivo e alvo da concupiscência e lascívia do mundo, e o "insulto" só deixava o resto do planeta com mais desejo que nunca ( $p .12)$.
\end{abstract}

Nova York, com a sua característica de ser um exemplo de local onde centro e periferia se sobrepõem, descentralizando qualquer idéia de cultura nacional monolítica, é o cenário onde o protagonista transita. É o símbolo máximo do cosmopolitismo, encravado no coração de uma América que ainda luta para manter o seu status hegemônico no panorama mundial.

Solanka abandona a vida acadêmica em Londres devido à sua estreiteza, às rivalidades e ao "extremo provincianismo" (p.21). Parte em busca do sonho. Mas, como nos lembra Calvino, ao referir-se às suas Cidades Invisíveis (1990), os sonhos e as cidades são construídos por desejos e medos. Nova York será para Solanka o lugar onde o desejo e o medo tornar-se-ão realidade.

O homem que busca esconder-se de si mesmo vê na grande Babel um bom lugar para viver:

Havia um anonimato gostoso nas multidões, uma ausência de intromissão. Ninguém estava interessado em seus mistérios. Todos estavam ali para se perder. Era essa a magia inarticulada das massas, e aqueles dias em que se perdia eram praticamente o único propósito da vida do professor Solanka (p.13).

A história pessoal de Solanka emerge à medida que entra em cena a primeira das três mulheres: Eleanor Masters. As lembranças que se assomam à sua memória revelam ao leitor como se deu o início do relacionamento entre os dois, que culminou em quinze anos de vida em comum. Muito embora a narrativa seja aparentemente direcionada à apresentação de Eleanor como personagem, é possível percorrer o caminho inverso e observar que há uma intenção subjacente de delinear a personalidade do protagonista a partir da visão da mulher. 
Não é gratuitamente que Rushdie constrói uma personagem que, além de bela e inteligente, enuncia, a propósito de sua tese de doutorado, uma frase que antecipa e determina a complicada relação de Solanka com as mulheres:

Otelo só ama a si mesmo, a si mesmo como amante e como líder, coisa que Racine, um escritor mais enfático, teria chamado de sua flamme, sua glorie. Ela não é nem uma pessoa para ele. Ele a coisifica. Ela é a sua estatueta Oscar-Barbie. Sua boneca [grifo nosso] (p.19).

A imagem da boneca surge no romance revestida de um simbolismo duplo. Ela não só é símbolo de um passado que está na origem da frustração e da fúria de Solanka, como também antecipa o papel que a boneca Little Brain passará a ter mais tarde em sua vida, vindo, inclusive, a ser a causa declarada do fim de seu casamento com Eleanor.

A "excentricidade" de Solanka, segundo a visão de seus colegas do King's College, começou após uma viagem a Amsterdã, onde visitou o Rijksmuseum e "entrou em transe diante da exposição do tesouro de casas de bonecas antigas" (p.22). Ao retornar a Cambridge, começou a construir os seus próprios microcosmos, passando mais tarde para os bonecos, mais precisamente uma série chamada de "Grandes Mentes". Quando se demitiu, anos depois, esses bonecos, que representavam os grandes filósofos da história, entrevistados pela boneca Little Brain, sua mais preciosa criação, tornaram-se a maior audiência da televisão.

Mas o sucesso exigia uma audiência ainda maior. E, quando o formato original foi considerado excessivamente intelectual pelos executivos do canal, Little Brain deixou de ser a "sua" criação, passando a ser a estrela de um novo show, voltado para a comédia e para o gosto das massas, a fim de garantir a audiência. Seu nome continuava nos créditos, obtinha uma parte razoável do merchandising, mas não conseguia mais assistir ao programa. A criação havia superado seu criador.

Se as transformações sofridas por sua criatura o agrediam, o mesmo não se podia dizer da renda que ela lhe proporcionava:

A ambição o comprometia e as concessões selavam seus lábios. Preso por contrato a não atacar a galinha dos ovos de ouro, teve de estrangular suas idéias e, para manter essa posição, encheu-se da amarga bile de seus muitos descontentamentos. A cada nova iniciativa da mídia liderada pelo personagem que um dia delineara com tamanha vivacidade cuidado, crescia sua fúria impotente (p.121). 
A fúria o leva, munido de uma faca, após uma memorável bebedeira, ao quarto, onde sua esposa e seu filho dormem. A súbita consciência de estar ali, completamente dominado por um sentimento irracional, diante de dois seres inertes, leva-o a abandonar a família e partir para a América.

Mas para qual América Solanka foge? Para a América que se faz cosmopolita por abrigar indivíduos oriundos de outros países, detentores das mais diversas culturas e de inúmeras etnias, ou a América consumista e disseminadora do ideal imperialista?

Solanka foge da própria fúria, ou melhor, das suas prováveis conseqüências, mas também da incômoda certeza de ter-se rendido à sociedade de consumo em troca de dinheiro e riqueza.

O local de exílio que busca é uma América ruidosa, cujo barulho aumenta quase que diariamente (p.55), capaz de absorvê-lo, degluti-lo, digeri-lo em meio à massa anônima:

Uma divindade maior estava à sua volta: a América, no auge do seu poder híbrido, onívoro. A América para onde tinha vindo para se apagar. Para se libertar de ligações e também da raiva, do medo e da dor. Engula-me, orou em silêncio o professor Solanka. Engula-me, América, e me dê paz (p.57).

Ao situar seu romance em Nova York, Rushdie pisa o campo minado que relaciona referências locais e universais, regionais e cosmopolitas, nacionais e internacionais. A via de acesso à mobilidade e visibilidade mundial, sem perder a fidelidade aos dados e referências locais, é o grande desafio do homem traduzido.

Criar uma personagem que busca o auto-exílio por causa da massificação de suas idéias e situá-la em um romance pródigo em citações e referências aos ícones da sociedade de consumo pode parecer uma incongruência.

O paradoxo aparente pode confundir o leitor semântico (ECO, 2003, p.208), porém dificilmente ludibriará o leitor semiótico, ou estético. A ironia intertextual é detectável na oposição entre os recursos discursivos e a narração.

Édouard Glissant (1996, p.121) afirma que só há um modo de combater o "universalismo desenraizado", ou seja, o universal imposto pelo ocidente: (d)escrever o seu mundo específico, pois "só há universalidade quando, do recinto particular, a voz profunda grita". 
O grito de Solanka, silenciado por seus próprios medos, se traduz em fúria. Ela quase o levara a matar sua mulher e seu filho; ela o levara à América, em busca de esquecimento. Mas a própria cidade lhe mostra que não há como fugir do som e da fúria:

A cidade estava Ihe dando uma lição. Não havia como escapar da invasão, do barulho. Atravessara o oceano para separar sua vida da vida. Viera em busca de silêncio e encontrara um ruído maior que aquele que deixara para trás. O ruído agora estava dentro dele (p.61).

Outrora, quando ainda estava casado com a sua primeira mulher, Sara Lear, ele já havia experimentado aquela sensação:

A vida é fúria, ele havia pensado. Fúria, sexual, edipiana, política, mágica, brutal, nos leva aos nossos melhores picos e às mais grosseiras profundezas. Da fúria nasce a criação, a inspiração, a originalidade, a paixão, mas também a violência, a dor, a destruição pura e destemida, o dar e receber golpes dos quais nunca nos recuperamos. As Fúrias nos perseguem (p.41).

A omissão da origem faz parte do jogo do esquecimento. Quando dialoga com Skywalker, evita mencionar sua condição de migrante: "Você é britânico, certo", continuou Skywalker (Solanka não entrou nas gentilezas pós-coloniais, migratórias)" (p.46).

A princípio, só Ihe interessa saber que deixara para trás a Inglaterra, o país da reserva, da discrição e do não-dito, trocando-a pelo país do diminutivo. A simples menção à sua pretensa nacionalidade inglesa faz emergir um outro acesso de fúria.

O homem que criara para cada um de seus bonecos uma história gostaria imensamente de apagar a sua:

Era isso que trazíamos em nossas viagens pelos oceanos, atravessando fronteiras, passando pela vida: nosso pequeno armazém de anedotas e do que aconteceu depois, nosso era-uma-vez pessoais. Éramos nossas histórias e quando morríamos, com sorte, nossa imortalidade estaria em uma dessas histórias. Essa era a grande verdade contra a qual Malik Solanka havia se colocado. Era precisamente sua história pregressa que ele queria destruir. Não importa de onde ele viera, nem quem, quando o pequeno Malik mal sabia andar, havia abandonado sua mãe e assim the dado permissão, anos depois, para fazer o mesmo.(...) Tinha vindo à América como tantos antes dele para receber a bênção de passar pela Ilha Ellis, de começar de novo. Me dê um nome, América, faça de mim um Buzz ou Chip ou Spike. Mergulhe-me em amnésia e me vista em seu poderoso desconhecimento. Me aliste na sua J. Crew e me dê minhas orelhas de rato! Não mais um historiador, mas um homem sem histórias me permita ser. Arranco da garganta minha língua-mãe e falo o seu inglês torto no lugar (p.65). 
Homem voluntariamente exilado, Solanka experimenta a trajetória do migrante; trajetória que se assemelha, guardadas as devidas proporções, a do próprio autor, que tendo partido de Bombaim para a Inglaterra, onde estudou e esteve sob proteção durante a fatwa determinada pelo Aiatolá Khomeini, elegeu os EUA como o seu lugar de refúgio.

A literatura que nasce da migração do escritor, conforme afirma Júlio Monteiro Martins (Gnisci, 2001, p.114), é um tipo de sincretismo literário - temático e estilístico - uma conseqüência natural do condicionamento e da mudança no curso do estilo de vida dos escritores migrantes: o exílio, o cosmopolitismo, o multilingüismo, a migração e a fuga.

Assim sendo, Solanka funciona até certo ponto como porta-voz do autor no processo de difusão de suas idéias e crenças, ainda que veladamente, como sugere Armando Gnisci, em "Lettere Migranti” (2003, p.173) ${ }^{4}$ : “O escritor migrante, ainda que não escreva sobre a migração, a transforma em poética, como tema comum e como pedra de tropeço e confronto no mundo em que vivemos (vide Rushdie, Kureishi e Walcott)".

A evidência da crítica à hegemonia norte-americana se revela nas reflexões de Solanka sobre as mutações de caráter sofridas pelo amigo, Rhinehart:

Esse mesmo Jack podia agora se colocar lado a lado com os grandes
chefes do mundo, e, Solanka se deslumbrou, mais uma vez, com a
capacidade humana de automorfose, a transformação do eu, que os
americanos reivindicavam como sua característica especial e definidora.
Não era. Os americanos estavam sempre rotulando coisas com o logotipo
América: Sonho Americano, Búfalo Americano, Grafite Americano, Maluco
Americano, Canção Americana. Mas todo mundo tinha coisas assim
também, e no resto do mundo o acréscimo de um prefixo nacionalista
parecia não acrescentar muito sentido. Maluco Inglês, Grafite Indiano,
Búfalo australiano, Sonho Egípcio, Canção Chilena. A necessidade
americana de tornar as coisas americanas para se apossar delas, pensou
Solanka, era sinal de uma estranha insegurança. E também, claro, mais
prosaicamente de capitalismo (p.70).

Solanka é capaz de detectar na história de Rhinehart o escuro leito onde crescem as sementes da fúria, o segredo sombrio que o outro acalentava, seu desejo de ser aceito no "mundo dos homens brancos", segredo que não confessava a ninguém e, talvez, nem a si mesmo. No entanto, estava sempre buscando meios para ignorar a origem da raiva que trazia dentro de si.

\footnotetext{
$4 \quad$ Texto original: "Lo scrittore migrante, anche se non scrive sulla migrazione, sa tutto questo e lo pone come poética, come tema comune e come pietra di paragone e pietra d'inciampo dell'epoca in cui viviamo (vedi Rushdie, Kureishi e Walcott)". Minha tradução.
} 
Quando é apresentado à indiana Neela e se vê irremediavelmente preso à sua beleza, Solanka descobre o tamanho da cratera deixada pelo seu rompimento com o passado. Vê nela não só a imagem que criara da mulher ideal, mas também o elo com as origens que lutava para apagar: "Até as lojas naqueles arredores tinham nomes indianos. Tudo conspirava para fazê-lo lembrar o que estava querendo esquecer, ou seja, o lar, a idéia de lar em geral e a do lar de sua vida em particular" (p.87).

O acordar para a realidade faz com que Solanka perceba a incoerência da fuga, a falha ao atribuir àquela cidade a capacidade de resgatá-lo das profundezas do seu medo.

Sim, ela o tinha seduzido, a América, sim, seu brilho o excitara, e sua vasta potência também, e estava comprometido nessa sedução. Aquilo a que se opunha nela, tinha de atacar também em si mesmo. Ela o fazia desejar aquilo que prometia e eternamente retinha. Todo mundo era americanizado agora: indianos, iranianos, uzbeques, japoneses, liliputianos, todos. A América era o parque de diversões do mundo, seu livro de regras e árbitro e bola. Até o antiamericanismo era americanismo disfarçado, contanto que aceitasse, como aceitava, que a América era o único jogo a ser jogado e a matéria da América o único negócio (p.107).

A ambivalência de sentimentos é típica dos homens traduzidos. Seres obrigados a "aprender a habitar, no mínimo, duas identidades, a falar duas linguagens culturais, a traduzir e negociar entre elas" (HALL, 1998, p.89). A tentativa de unificar essas identidades passa pelo sentimento de culpa em relação à casa/pátria abandonada e à atração pela "casa do depois", a pátria de adoção (GNISCI, 2003, p.10).

No âmago dessa ambivalência está a consciência de que a diversidade cultural é uma questão política fundamental para o futuro das sociedades de um pólo ao outro. O papel da literatura como disseminadora dessa diversidade continua a ser determinante, pois a estratégia de dominação ainda continua sendo a tentativa de uniformização e estandardização da cultura, de imposição da lógica ocidental singular à pluralidade cultural dos povos que não fazem parte do "centro". E a Nova York que Rushdie retrata é a Meca desse jogo. 
A surpreendente precisão espaço-temporal de Fúria se deve, principalmente, à avalanche verborrágica de referentes impostos pela mídia: a enumeração de nomes de atores, atrizes, modelos, programas de televisão, filmes e objetos de consumo.

Mila, a encarnação de uma América movida à tecnologia, surge no panorama de indefinições e ambivalências em que a vida de Solanka se transformara como uma possibilidade de encontro com o self. É a ela que ele conta parte de sua história: a criação da boneca, o fim do casamento e o ato absurdo que cometera, ao pensar em pôr fim à vida da mulher e do filho. Em retribuição, ela Ihe conta a sua história, ou melhor, a história de seu pai, Milosevic, que morrera em luta na Croácia. A história de um grande amante, poeta, ainda que desconhecido, que um dia embarcara para dentro da fúria.

É Mila quem enuncia em tom profético que "a América, por causa da sua onipotência está cheia de medo. Tem medo da fúria do mundo e rebatiza isso de inveja" (p.136).

O jogo de sedução de Mila faz com que Solanka suspeite que tenha havido uma relação incestuosa entre ela e o próprio pai, mas nem assim consegue resistir às suas estratégias, afirmando para si mesmo que "um mortal que faz amor com uma deusa está condenado, mas uma vez escolhido não pode evitar seu destino". É graças a um pedido dela que retoma a atividade de fazer bonecos e, mais tarde, aceita participar da criação de um website de sci-fi, cujas personagens são seus bonecos.

Quando, repentinamente, Neela torna a entrar em sua vida, Solanka descobre que aquela mulher é capaz de, com um simples gesto, aplacar a sua fúria. Após a investida de um jovem admirador da beleza de Neela, que tomara Solanka por seu pai, a fúria se apossa dele, incontrolável, desejosa de morte, sangue e dor, mas é surpreendentemente contida pela mão da moça em seu braço.

O fenômeno, a imprevisível subida e descida de seu temperamento, foi tão rápido que Malik Solanka ficou tonto e confuso. Teria acontecido de fato? Teria estado realmente à beira de despedaçar membro a membro aquele sujeito hiper em forma? E se assim fosse, como Neela havia dissipado a sua raiva (a raiva que Solanka tinha de combater ficando às vezes horas no quarto escuro,fazendo exercícios respiratórios e visualizando triângulos vermelhos) com um mero toque? A mão de uma mulher podia realmente possuir tal poder? E se assim fosse (a idéia lhe veio sozinha, não havia 
como negá-la) não seria essa uma mulher para manter ao seu lado e estimar pelo resto da sua assombrada vida? (p.176-177)

Com Mila de um lado, a impulsionar o seu poder criativo, e Neela do outro, a preencher o espaço destinado à última grande aposta emocional da sua vida, Solanka parece rumar para o equilíbrio.

O passado do qual Solanka passara a vida fugindo, finalmente, é revelado a Neela: a mágoa profunda pelo abandono do pai que jamais chegara a conhecer e do qual sequer sabia o sobrenome; pela rapidez com que a mãe o substituíra em menos de um ano por um outro homem, conferindo-lhe o sobrenome do padrasto, roubando-Ihe a sua história; principalmente, pela crueldade que lhe fora imposta, ao vestirem-no de menina, em substituição à filha que Mrs. Solanka não tivera, e pelos constantes abusos sexuais por parte do padrasto. A intervenção do pai de seu amigo Chandra livrara-o do pesadelo, dos trajes de menina, dos laços e fitas. Mas não havia querido separar-se das bonecas. As bonecas - a única família em que conseguira acreditar.

O capítulo 12, que retrata o mundo de sci-fi criado por Solanka, apresenta seis diretrizes que são uma retomada intertextual de Six Memos for the Next Millennium, de Ítalo Calvino (1988). Nessa obra, Calvino conjetura sobre o destino da literatura e dos livros na era tecnológica, sugerindo que há necessidade de alguns argumentos retóricos para atrair o leitor: a "leveza" - em oposição ao peso e à opacidade do mundo; a "rapidez" - em oposição à lentidão de digressões ou de narrativas detalhistas; a "exatidão" - em oposição à generalidade, à vagueza; a "visibilidade" - em oposição ao abstrato, conceitual; a "multiplicidade" - em oposição ao texto longo, com uma única voz, e, por último, a "coerência".

Ao atribuir a Kronos, o criador de bonecos do universo de sci-fi, a elaboração desses "seis altos valores", Rushdie redefine a perspectiva de Calvino.

Leveza, rapidez, exatidão, visibilidade, multiplicidade, coerência: esses eram os seis altos valores kronosianos, mas em vez de gravar definições únicas desses princípios nos programas default dos cyborgs, ofereceu a suas criações uma série de múltiplas escolhas. Assim, "leveza" podia ser definido como "fazer com leveza o que é na realidade uma tarefa pesada", isto é, graça; mas também podia ser "tratar com frivolidade o que é sério", ou mesmo "tornar leve o que é grave", ou seja a amoralidade. E "rapidez" podia ser "fazer depressa tudo o que for necessário", em outras palavras, eficiência; porém se a ênfase fosse colocada na segunda parte da frase, resultaria em uma espécie de crueldade. "Exatidão" podia tender para "precisão" ou "tirania", "visibilidade" podia ser "clareza de ação" ou "busca de atenção", "multiplicidade" podia ser ao mesmo tempo "abertura de 
cabeça" e "duplicidade", e "coerência", o mais importante dos seis, podia significar tanto "confiabilidade" como "obsessão"... (p.196 - grifos do autor).

Quando Kronos perde o controle sobre as suas criações (repetindo a própria história de Solanka), ele escreve: "Aqui a vida artificial meramente espelha a realidade. Pois o homem nasce acorrentado, mas busca em toda parte a liberdade" (p.199).

Ao final do capítulo, há uma série de perguntas que resume as alternativas disponíveis não só para os Reis Bonecos, mas extensíveis a Solanka, enquanto persona do autor no universo ficcional, e ao próprio Rushdie, enquanto escritor e homem :

Kronos havia oferecido aos Reis Bonecos uma opção entre os seus eus originais, mecânicos, e pelo menos algumas das ambigüidades da natureza humana. Qual seria a escolha deles: a sabedoria ou a fúria? A paz ou a fúria? O amor ou a fúria? A fúria do gênio, da criação, ou a do assassino ou tirano, a louca fúria estridente que não deve ser nunca nomeada? (p.200)

As mesmas características enunciadas por Kronos, e aplicadas ao capítulo 12 por Rushdie, são igualmente detectáveis em todo o romance. A "leveza" encontra seu exemplo máximo na cena em que Solanka, nu, se vê diante das três mulheres que amara, à espera de uma explicação, visualizando, por seu intermédio, a imagem das três Fúrias. Rushdie retrata Tisífone, Alecto e Megera com o olhar do homem pós-moderno, sem negar à cena a complexidade e a força do mito.

Para Ítalo Calvino, "exatidão" significa uma obra bem definida e calculada, que leva à evocação de imagens nítidas, por meio de uma linguagem precisa. Mas como ser exato nas artes, a partir do momento em que o mundo que inspira os artistas é multicultural, multinacional, multiforme, onde circulam milhares de informações simultaneamente? Por meio de um compromisso com a realidade. A cada página do romance é possível reconhecer os fatos do nosso mundo contemporâneo, ainda que vistos sob uma ótica irônica. Não temos dúvida de que é sobre o mundo em que vivemos que o autor escreve.

O texto fluido, conciso, não deixa a menor dúvida sobre o cumprimento do princípio da "rapidez". Para Calvino, a rapidez de estilo e de pensamento significa "agilidade, mobilidade, desenvoltura"; qualidades essas que se combinam com uma escrita propensa às divagações, a saltar de um assunto para outro, a perder o fio do relato para reencontrá-lo ao fim de inumeráveis circunlóquios. 
O princípio da "multiplicidade", segundo Calvino, é uma marca do romance contemporâneo, que funciona como enciclopédia, como método de conhecimento, como visão pluralística e multifacetada do mundo. A "multiplicidade" prolifera nas múltiplas visões de um mesmo fato, nos múltiplos discursos imbricados em um mesmo romance, na consciência da simultaneidade e da diferença, fatores esses extremamente presentes no romance de Rushdie. São inúmeros os intertextos detectáveis no romance, as vozes oriundas de outros discursos. Algumas identificáveis por meio de alusões, outras por traços intertextuais de forma e/ou conteúdo. A própria detecção do texto de Calvino em Fúria é um exemplo dessa multiplicidade.

A "visibilidade" evoca a força poética do imaginário, a visão profética tanto do passado quanto dos espaços Iongínquos, como disse Glissant (1996, p.67). É essa visão que o autor invoca na trajetória de Solanka, sugerindo que a experiência e a fantasia são compostas pela mesma matéria verbal.

As desventuras de Solanka rumo ao desfecho do romance levam-no, novamente, ao auto-exílio, trancado em um quarto de hotel, ruminando a perda de Neela; até que decide ver Asmaan, seu filho, que tantas e tantas vezes Ihe implorara para voltar para casa. Encontra-o de mãos dadas com o atual padrasto, como um filho apoiando-se em seu pai, e é acometido pela dor da perda. Passara muito tempo fugindo de si mesmo, dos seus medos e da fúria. Agora, decide subir no castelo de pular, saltar na plataforma elástica até que o filho o veja "invocando todo o seu amor perdido e arremessando esse amor alto no céu como um pássaro branco" (p.304).

A voz do homem que não se encontra em seu próprio destino, do expatriado que não identifica em lugar nenhum o seu local de origem, do homem da nossa era, sujeito à ação avassaladora da aceleração do tempo, emerge em uma última tentativa de encontrar o seu paraíso. Finalmente, reconhece que o seu paraíso sempre estivera ao seu alcance. Fora criado por ele mesmo; era seu filho Asmaan, cujo nome significa "céu", "paraíso", em urdu.

A semelhança física de seu filho com Little Brain não é mera coincidência. Solanka passara a vida brincando de Deus, obsessivamente (eis aqui a "coerência" na perspectiva reelaborada de Rushdie) dando vida a criaturas que, cedo ou tarde, 
libertavam-se do seu criador, partindo para forjar seu próprio destino. Fora assim com Little Brain, com Kronos, e, agora, chegara a vez de Asmaan.

Reivindicar para si o papel de pai passa a ser crucial. Equivale a recuperar a identidade perdida. Significa também uma opção pelo amor. O grito que ecoa de sua garganta, tentando atrair a atenção do filho, é a sua última tentativa de fugir à pergunta que sempre martelara a sua cabeça: "Quem está puxando as cordinhas para as marionetes dançarem?" (p.15).

Em Fúria, Salman Rushdie traz à baila elementos inerentes à condição do migrante: a necessidade de recuperar o sentido de pertencimento, a dificuldade de lidar com uma identidade híbrida e transcultural, bem como os meios de ancoragem dessa nova identidade.

Ao fim do romance, ele permite que Solanka encontre a resposta para todas as suas dúvidas e indagações. Para ele, ser reconhecido por Asmaan representa tudo: a recuperação do self e a certeza de não ser mais um boneco na mão de um fazedor de bonecos capaz de criar um mundo cheio de som e de fúria. 


\section{REFERÊNCIAS}

AUGÉ, M. Não-lugares. Trad. Lúcia Muznic. Portugal: Bertrand, 1994.

CALVINO, I. Six memos to the next millenium. Cambridge: Harvard University Press, 1988.

CALVINO, I. Cidades invisíveis. São Paulo: Cia das Letras, 1990.

ECO, U. Sobre a literatura. Trad. Eliana Aguiar. Rio de Janeiro: Record, 2003.

GLISSANT, E. Introduction à une poétique du divers. Paris: Gallimard, 1996.

GNISCI, A. Creolizzare I'Europa. Letteratura e migrazione. Roma: Meltemi, 2003.

GNISCI, A. Una storia diversa. Roma: Meltemi, 2001.

HALL, S. A identidade cultural na pós-modernidade. Trad. Tomaz Tadeu da Silva e Guacira Lopes Louro. Rio de Janeiro: DP \& A, 1998.

ORTIZ, F. Contrapunteo cubano del tabaco y azúcar. La Habana: J. Montero, 1940.

RUSHDIE, S. Fúria. Trad. José Rubens Siqueira. São Paulo: Companhia das Letras, 2003.

RUSHDIE, S. Imaginary Homelands. Londres: Granta Books, 1991.

SAID, E. W. Narrative and geography. New Left Review, n.180, p. 81-100, mar./abr. 1990. 